\title{
A Retrospective Study of All Low Birth-Weight Preterm Babies Born in BMH Rinteln Between 1980-1989
}

\author{
Mary E Crowther \\ MD, MRCOG \\ Consultant Obstetrician \& Gynaecologist \\ British Military Hospital, Rinteln, BFPO 29
}

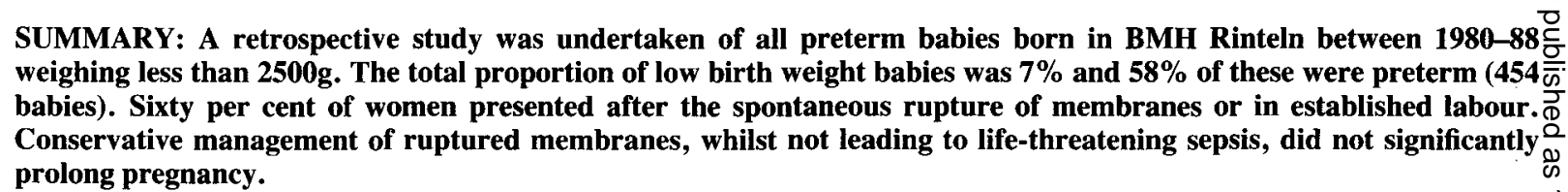

Sixteen percent of the babies were very low birth weight (under 1500g). Delivery of these infants by Caesarean section $\overrightarrow{0}$ when presenting by the breech improved survival, although this was not statistically significant. Thirty percent of all $\vec{\exists}$ babies were delivered by Caesarean section before 36 weeks, reflecting obstetric emergencies in the mother which $\bar{\rho}$ predisposed to preterm delivery.

Neonatal survival depended on both gestational maturity and birth weight and was not significantly better in babies who were low birth weight for gestational age. These infants however represented $75 \%$ of the still-births and congenital abnormalities.

Sixty percent of the mothers smoked and $\mathbf{5 0} \%$ had other identifiable risk factors for preterm delivery; $20 \%$ of the multiparous patients had previously experienced a perinatal death, preterm delivery or had a baby with intra-uterine $\rightarrow$ growth retardation. It is suggested that preterm delivery is a significant problem in an Army population despite fọ 1 강 employment, adequate housing and comprehensive medical care. Attempts to stop labour are unlikely to be successfiul. 음 Effort should be made antenatally to identify those women who may be at risk of "idiopathic" preterm labour, as patient education programmes have been shown to decrease the incidence.

\section{Introduction}

Premature birth (before the 37th completed week of gestation) occurs in $6-8 \%$ of all pregnancies in the UK, but contributes to $70 \%$ of all perinatal deaths ${ }^{1}$. In $40 \%$ of cases there is no obvious cause; in $30 \%$ the pregnancy is electively terminated because of a serious complication such as hypertension; and in $30 \%$ there is an obvious cause such as multiple pregnancy or chorioamnionitis ${ }^{2}$. Certain risk factors have been identified: race $^{3}$, extreme youth, low socio-economic status ${ }^{4}$, low pre-pregnancy weight and small stature ${ }^{5}$, smoking ${ }^{6}$, genital infection ${ }^{7}$, bleeding early in pregnancy, previous preterm delivery ${ }^{8}$ and stress ${ }^{9}$. Attempts to quantify these risks have been successful in identifying over $60 \%$ of those destined to deliver preterm ${ }^{10}$.

The morbidity associated with the care and survival of preterm babies, particularly those less than $1500 \mathrm{~g}$ is significant ${ }^{11,12,13}$. The family repercussions of separation from the infant are far-reaching and may consist of poor bonding, neglect and abuse of the child, difficulties in coping if the child is handicapped, and inappropriate grieving should death occur ${ }^{14}$.

A retrospective study of preterm birth in $\mathrm{BMH}$ Rinteln resulting in babies less than $2500 \mathrm{~g}$ was therefore undertaken to investigate both epidemiological factors and outcome.

\section{Methods}

Data were obtained from the delivery books at $\mathrm{BMH}$
Rinteln which recorded all births from the beginning a 1980 to the end of 1988 . It was not possible to identify aी preterm births from these books as gestation wars $\overrightarrow{0}$ sometimes recorded incorrectly. Therefore only babi@ $\Theta$ who weighed less than $2.5 \mathrm{~kg}$ at birth were included the study.

The case notes were then obtained to assess whethet the baby was genuinely preterm, or a growth retarded baby born after this time. In 31 cases mother's notes could not be found; however, notes on all babies were obtained from the admission books to the Special Care Baby Unit (SCBU), and on all mothers details of the delivery were obtained from the delivery register.

\section{Results}

Between 1980-88, 11,029 babies were born in BMH Rinteln, of which $777(7.0 \%)$ weighed between $500-3$ $2500 \mathrm{~g}$. Of these, $454(58.4 \%)$ were born preterm to $421 \overrightarrow{\widetilde{\Phi}}$ mothers. Medical records could not be traced in $31 \stackrel{\varrho}{\rightleftharpoons}$ cases, leaving notes on 420 babies delivered to 390 mothers. Aspects of delivery are shown in Table 1 for 3 each of the 3-year periods of the study.

Table 2 shows that 255 women $(60.5 \%)$ presented in $\frac{0}{3}$ early or established labour, or following the spontaneous rupture of membranes (SRM). The remainder had some other medical complication which $\frac{D}{0}$ necessitated terminating the pregnancy. Twins (42․ pairs) and 1 case of triplets accounted for $10.2 \%$ of all $\mathbb{N}$ cases. 
Table 1

Aspects of Preterm Low Birth Weight Deliveries, BMH Rinteln, 1980-88

\begin{tabular}{|c|c|c|c|c|}
\hline & $1980-2$ & $1983-5$ & $1986-8$ & Total \\
\hline All babies born & 3880 & 3873 & 3276 & 11,029 \\
\hline All LBW ( $\%$ of total) & $(8.3 \%)$ & $(6.3 \%)$ & $(6.4 \%)$ & $777(7.0 \%)$ \\
\hline
\end{tabular}

Proportion of LBW babies

born preterm

$182(56.3 \%)$

Preterm twins

$14(8.2 \%)$

$29(15.9 \%)$

$25(14.6 \%)$

Breech presentation

Still-births (SB)

Neonatal-deaths (NND)

11) $(14.3 \%)$

Caesarean section

Induction of labour

$39(22.8 \%)$

$28(16.4 \%)$

$144(59 \%)$

$128(60.9 \%)$

$454(58.4 \%)$

Iatrogenic prematurity

$13(7.1 \%)$

$12(8.8 \%)$

$26(18.1 \%)$

$17(14.9 \%)^{*}$

$21(16.4 \%)$

$43(10.2 \%)$

$24(17.6 \%)$

$28(24.6 \%)$

$76(16.7 \%)$

11) $(12.5 \%)$

5) $(10.9 \%)$

$77(16.9 \%)$

${ }^{*} 1$ case of triplets

Percentages are given as proportion of all preterm babies or deliveries

Table 2

\section{Aetiological Factors in the Delivery of Preterm Babies, 500-2500 g}

\begin{tabular}{|c|c|c|c|}
\hline \multirow{2}{*}{\multicolumn{2}{|c|}{$\begin{array}{l}\text { Factor } \\
\text { Premature onset of labour or } \\
\text { spontaneous rupture of membranes }\end{array}$}} & \multicolumn{2}{|c|}{ Number } \\
\hline & & 255 & $(60.5 \%)$ \\
\hline $\begin{array}{l}\text { Elective Caesare } \\
\text { (Rhesus disease, } \\
\text { CTG, suspected I } \\
\text { section, scar tend } \\
\text { suspected fetal ab }\end{array}$ & $\begin{array}{l}\text { section } \\
\text { normal antenatal } \\
\text { GR, previous } \\
\text { ness, fibroids, } \\
\text { ormality) }\end{array}$ & 14 & $(3.3 \%)$ \\
\hline Abruption & $\{\mathrm{APH}$ & 15 & $(3.6 \%)$ \\
\hline Placenta praevia & ) & 13 & $(3.1 \%)$ \\
\hline \multicolumn{2}{|c|}{$\begin{array}{l}\text { Other complications (hypertension, } \\
\text { PIH, intra-uterine death, IUGR) }\end{array}$} & 104 & $(24.7 \%)$ \\
\hline \multirow{2}{*}{\multicolumn{2}{|c|}{$\begin{array}{l}\text { Iatrogenic induction of labour or } \\
\text { Caesarean section }\end{array}$}} & 20 & $(4.8 \%)$ \\
\hline & & 421 & $(100 \%)$ \\
\hline
\end{tabular}

IUGR = intra-uterine growth retardation

PIH = pregnancy-induced hypertension

CTG = cardiotocograph

$\mathrm{APH}=$ antepartum haemorrhage

\section{Iatrogenic prematurity}

Twenty-two cases $(5.2 \%)$ of prematurity resultete from the elective termination of pregnancy calculation from a mistaken gestation. Induction of laberir ("logistic" in 16 cases and following SRM in 2 cases) ando elective Caesarean section (4 cases) was done after "30 weeks and resulted in the birth of babies 4-6 weecs smaller than calculated. One neonatal death fromis respiratory distress occurred. Twenty percent of the mothers had not had a scan, although the proportion on women scanned increased from $66 \%$ in the years $1980-\frac{2}{D}$ 2 , to $96 \%$ from $1986-8$.

\section{Management of preterm labour}

Ritodrine and steroids were used in 58/255 women $(22.7 \%)$ who presented in spontaneous labour or after SRM. Pulmonary oedema occurred in one case 3 . Premature SRM was managed conservatively in 37 cases $(14.5 \%)$ and labour was induced or began spontan eously more than 24 hours later in 27 cases. However the mean gestation was increased from 32.6 weeks on admission to only 32.9 weeks on delivery (range $26-37_{0}^{\circ}$ weeks). Eight women $(21.6 \%)$ had positive vagina $\mathrm{B}$. swabs for E.coli (1), Klebsiella (1) or Group B betahaemolytic Streptococcus (8) but no baby died from? sepsis.

Very low birth weight babies (VLBW)

Seventy-six women $(16.7 \%)$ delivered babies weighing less than $1500 \mathrm{~g}$. There were 49 vaginass deliveries $(64.5 \%)$, including 13 still-births. The mean 
gestation was 29.9 weeks (range 25-36 weeks), and the mean length of labour 3.7 hours (range 1-12 hours). Caesarean section was performed for fulminating Pregnancy Induced Hypertension (PIH) (8), Antepartum Haemorrhage (APH) (12) and breech presentation or unstable lie (7) in the remaining women.

\section{Management of breech presentation}

The outcome of 77 babies $(16.9 \%)$ presenting by the breech is shown in Table 3. Twenty-five babies $(32.5 \%)$ were part of a multiple pregnancy, $18(23.4 \%)$ died in utero or soon after birth and six $(7.8 \%)$ had gross abnormalities. Caesarean section was performed electively in 8 cases for Intrauterine Growth Retardation (IUGR) or breech-breech presentation; for

\section{Survival}

Figures 2 and 3 illustrate survival in relation to fetaB weight and gestational age. This was calculated for one month following delivery but includes one baby who died in SCBU 7 weeks after birth from sepsis and coagulopathy.

Table 5 shows the aetiology of all deaths. When birthe weights were plotted against Gairdner-Pearson charts: used for paediatric assessment, 152 babies $(36.2 \%)$ weres found to be of low birth weight for gestational ageo (LGA). This was suspected clinically or by ultrasound in듬 58 cases $(43.9 \%)$ and forms the basis of another report $\frac{\bar{\Phi}}{\bar{D}}$ Of babies who died in utero or had congenita $\mathbb{D}_{2}$ abnormalities, $75.9 \%$ were LGA.

Table 3

Mortality of Infants Presenting by the Breech According to Birth Weight and Mode of Delivery

\begin{tabular}{lllllllll}
\hline & & & & & \multicolumn{3}{c}{ Total Live Births } & ? \\
\hline Weight & Number & (SB) & Twins & $\begin{array}{c}\text { Mean gest. Caesarean } \\
\text { (weeks) }\end{array}$ & NND & Vaginal & NND & Sig. \\
\hline
\end{tabular}

less than

$1501 \mathrm{~g}$

24

(5) 5

29.8

$6(31.6 \%) 2(33.3 \%)$

$13(68.4 \%) 6(46.2 \%)$

$1501-2500 \mathrm{~g} \quad 53$

(1) 20

34.2

$29(55.8 \%) 2 *(6.9 \%)$

(6) $25(32.5 \%)$

$35(45.5 \%) \quad 4(11.4 \%) \quad 36(54.5 \%) 8(22.2 \%)$

Total $\mathrm{SB}=$ Still-birth

Total mortality $23.4 \%$

*all 4 with congenital abnomalies +2 SB with neural tube defects

fulminating PIH (6), APH (7), fetal distress (3) and extreme prematurity, unstable lie or footling presentation (8). The figures are too small to show whether Caesarean section improved the survival of VLBW babies, 2 of whom died from respiratory distress and intraventricular haemorrhage, compared with 6 from sepsis and respiratory distress after vaginal delivery. Difficulty in delivery of the fetal head occurred in one case only. It is not clear from the notes why some VLBW babies delivered vaginally, but the average length of the first stage of labour was 4.5 hours (range 40 minutes -12 hours) and in 3 cases the mother was admitted at full dilatation.

\section{Induction of labour and Caesarean section}

Labour was induced non-logistically in 64 women $(15.2 \%)$ and Caesarean section performed in 116 $(27.6 \%)$. In over $80 \%$ of cases this was necessitated by an acute obstetric emergency (Table 4) and there was one maternal death in a woman with fulminating PIH. Up to the 36th week $29.3 \%$ of pregnancies ended in Caesarean section compared with $16.7 \%$ in the 37 th week (Fig. 1). This was statistically significant ( $\mathrm{p}<$ 0.002 ). A classical incision was used to deliver VLBW babies ( 3 cases) and avoid fibroids in the lower segment ${ }^{1}$.
Table 4

Indications for Induction of Labour and Caesareant Section in Preterm Low Birth Weight Babies

\begin{tabular}{|c|c|c|}
\hline & $\begin{array}{c}\text { IOL } \\
n=64\end{array}$ & $\begin{array}{c}\mathrm{CS} \\
\mathrm{n}=116\end{array}$ \\
\hline $\begin{array}{l}\text { Elective (IUGR, fibroids, } \\
\text { breech, previous CS, } \\
\text { Rhesus disease, unstable } \\
\text { lie, previous SB) }\end{array}$ & & $14(12.1 \%)$ \\
\hline IUGR & $10(15.6 \%)$ & \\
\hline Fulminating PIH & $17(26.6 \%)$ & $25(21.6 \%)$ \\
\hline Antepartum haemorrhage & $2(3.1 \%)$ & $24(20.7 \%)$ \\
\hline $\mathrm{SRM} \pm$ infection & $14(21.9 \%)$ & $4(3.4 \%)$ \\
\hline Intra-uterine death & $21(32.8 \%)$ & \\
\hline $\begin{array}{l}\text { Fetal distress in labour } \\
\text { (6 following induction) }\end{array}$ & & $21(18.1 \%)$ \\
\hline $\begin{array}{l}\text { Breech presentation, cord } \\
\text { prolapse, unstable lie, } \\
\text { failure to progress }\end{array}$ & & $28(24.1 \%)$ \\
\hline
\end{tabular}




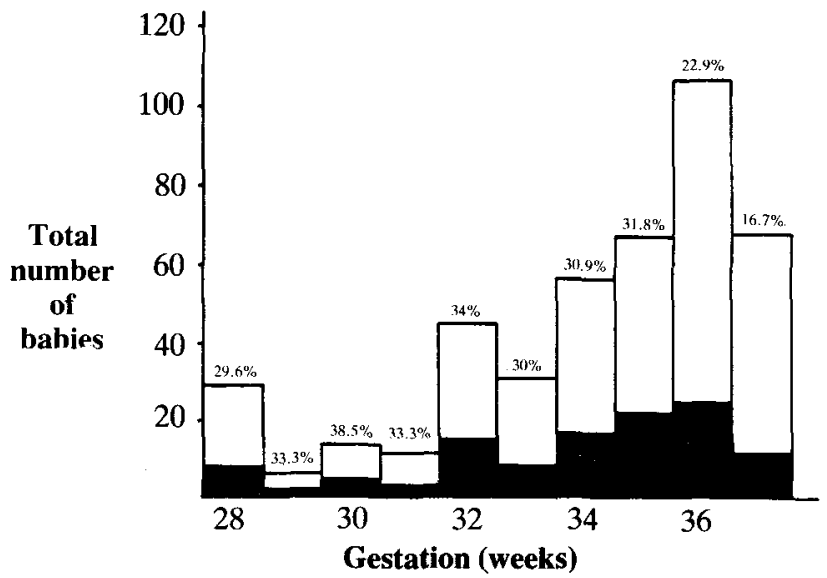

Fig. 1 Caesarean section rate in preterm infants less than $2500 \mathrm{~g}$ according to gestational age

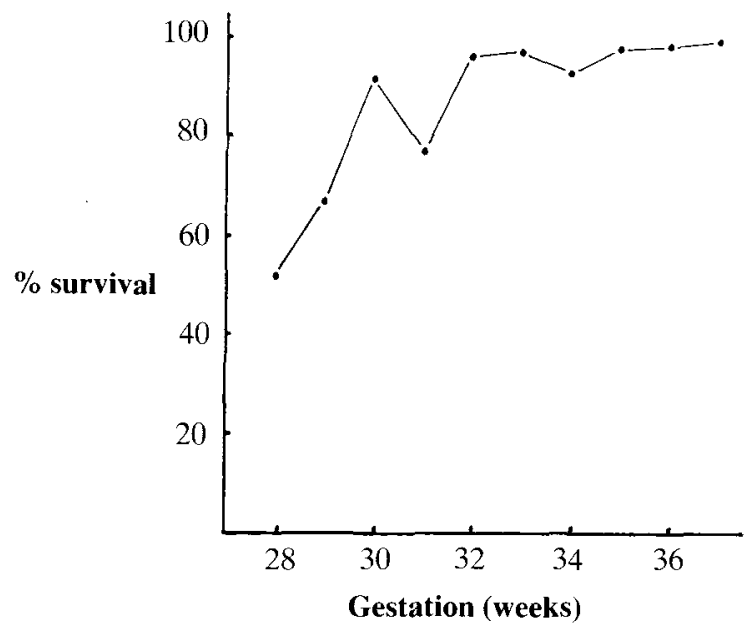

Fig. 3 Survival by gestational age of preterm infants less than $2500 \mathrm{~g}$

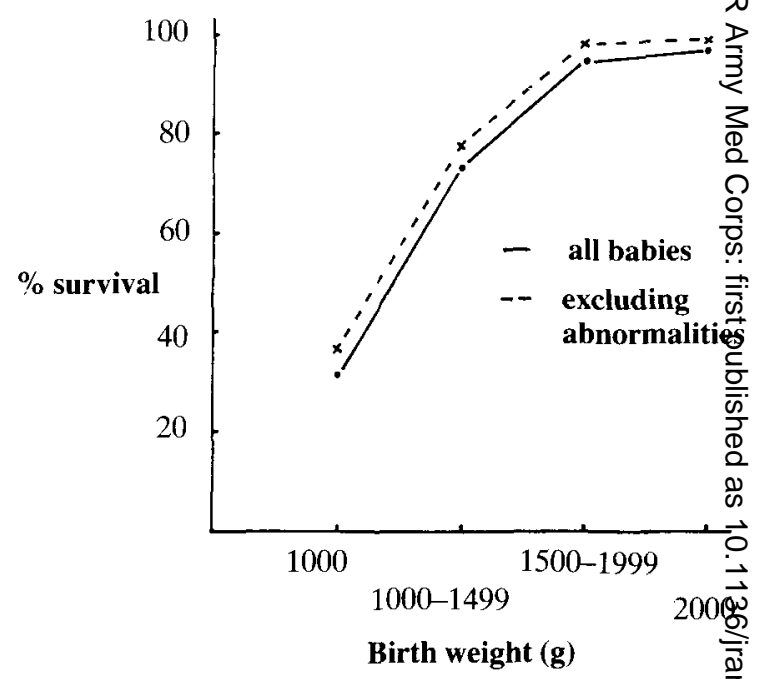

Fig. 2 Survival by birth weight of preterm infantes less than $2500 \mathrm{~g}$

Table 5

Aetiological Factors in the Mortality of Preterm Infants less than $2500 \mathrm{~g}$

\begin{tabular}{|c|c|c|c|}
\hline Still-births & Number & \multicolumn{2}{|c|}{$\begin{array}{l}\text { (proportiong } \\
\text { LGA) }\end{array}$} \\
\hline Intra-uterine death: & & & 包 \\
\hline Unknown aetiology & 16 & $(12)$ & о \\
\hline Congenital abnormalities & 5 & (3) & $\frac{0}{10}$ \\
\hline Abruption & 2 & (1) & $\stackrel{2}{\Rightarrow}$ \\
\hline Fulminating $\mathrm{PIH}$ & 2 & - & $\frac{0}{3}$ \\
\hline Intra-partum death: & & & $\underset{g}{2}$ \\
\hline Placenta praevia & 1 & (1) & סִ \\
\hline Congenital abnormality & 1 & (1) & $\underline{3}$ \\
\hline Total & 27 & $(18)$ & $\stackrel{\text { d) }}{2}$ \\
\hline Neonatal Death & & & $\begin{array}{l}\overrightarrow{\mathbb{D}} \\
\stackrel{\mathbb{N}}{=}\end{array}$ \\
\hline Congenital abnormalities & 10 & (9) & 字 \\
\hline Iatrogenic prematurity & 1 & - & $\underline{3}$. \\
\hline Abruption & 4 & (1) & 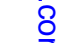 \\
\hline Respiratory distress & 16 & (4) & そ \\
\hline Total & 31 & (14) & 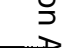 \\
\hline
\end{tabular}


The survival of LGA babies was similar to that for babies of appropriate weight but the still-birth rate was much higher (Table 6). About $60 \%$ of all babies spent more than 6 days in SCBU, but the total length of stay was significantly less for LGA babies. previous preterm delivery ${ }^{8}$ and psychological stress in $\longrightarrow$ pregnancy ${ }^{9}$. In the latter study, patients were asked about family arguments, death or illness in relatives or 3 friends, worry about the care of children while in hospital, marital conflict, physical violence and debt.

Table 6

Birth Weight and Gestational Maturity of Still-births and Survivors: Comparison Between Babies Appropriate and Low Birth Weight for Gestational Age

\begin{tabular}{|c|c|c|c|}
\hline & $\begin{array}{l}\text { Appropriate for } \\
\text { Gestational Age }\end{array}$ & $\begin{array}{c}\text { Low for } \\
\text { Gestational Age }\end{array}$ & Significance \\
\hline Still-birth rate & $9 / 302(2.9 \%)$ & $18 / 152(11.8 \%)$ & $\mathrm{p}<0.002$ \\
\hline Mean weight (g) & $1748.3 \mathrm{~g}$ & $1425.6 \mathrm{~g}$ & NS \\
\hline Mean gestation (weeks) & 31.8 weeks & 34.5 weeks & $\mathbf{P}<0.002$ \\
\hline \multicolumn{4}{|l|}{ Survivors } \\
\hline More than 6 days in SCBU & $167 / 276(60.5 \%)$ & $75 / 120(62.5 \%)$ & \\
\hline Mean length of stay (days) & 26.5 days & 18.8 days & $\mathrm{p}<0.001$ \\
\hline
\end{tabular}

Maternal risk factors

Nearly half the mothers in this study were primiparous and of the multiparous women, nearly $20 \%$ had previously experienced a preterm delivery, neonatal death or the birth of a LGA infant. Aspects of antenatal health such as smoking and anaemia did not improve significantly during the nine years (Table 7). Nineteen mothers $(4.8 \%)$ had amniocentesis early in the pregnancy following two raised serum alphafetoprotein estimates (AFP).

\section{Discussion}

Between 1980-89,7.0\% of all deliveries in BMH Rinteln resulted in an infant weighing less than $2.5 \mathrm{~kg}$. This compares with the national incidence of $7.21 \%$ in 1986 (Office of Population Censuses and Surveys). The proportion of LBW babies in fact fell from $9.1 \%$ in 1980 to $6.8 \%$ in 1988 . Approximately $60 \%$ of the babies, or $4.1 \%$ of all deliveries, were preterm. This is, however, a retrospective study, and because of inaccuracies in the recording of gestational age, it was necessary to look at an accurate value such as birth weight. The figure of $4.1 \%$ therefore underestimates the total number of babies born prematurely in this hospital. In 1988, 8.5\% of all deliveries occurred before the 37th completed week of pregnancy.

In most Western countries the incidence of preterm labour is $6-12 \%^{15}$ and incorporates a significant number of women with risk factors such as race, single motherhood, overt poverty and unemployment ${ }^{3,4,5,6}$. Such factors ostensibly do not exist in the Army population which is predominantly Caucasian and enjoys full employment. However, more subtle associations have been shown between preterm delivery and smoking ${ }^{6,9}$,
Table 7

Identifiable Risk Factors in 390 Mothers Who Delivered Preterm Infants Less Than $2500 \mathrm{~g}$

\begin{tabular}{|c|c|c|c|}
\hline & 1980-2 & 1983-5 & 1986- \\
\hline Scan at any stage & $66.2 \%$ & $84.4 \%$ & $95.6^{\circ}$ \\
\hline Primiparous & $46.8 \%$ & $50.0 \%$ & $47.4 \%$ \\
\hline Age less than 20 & $14.9 \%$ & $9.0 \%$ & \\
\hline Smoking & $58.4 \%$ & $51.6 \%$ & $57.0^{\circ}$ \\
\hline $\begin{array}{l}\text { Previous SB, NND, LGA } \\
\text { or preterm baby }\end{array}$ & $22.1 \%$ & $16.4 \%$ & $17.5 \%$ \\
\hline $\begin{array}{l}\text { Height less than } 150 \mathrm{~cm} \text { or } \\
\text { weight less than } 45 \mathrm{~kg}\end{array}$ & $11.7 \%$ & $13.2 \%$ & $9.6 \%$ \\
\hline $\begin{array}{l}\text { Haemoglobin less than } \\
10.5 \mathrm{~g} / \mathrm{dl} \text {. }\end{array}$ & $16.2 \%$ & $14.7 \%$ & $22.8 \%$ \\
\hline Breast feeding & $29.2 \%$ & $33.6 \%$ & $22.8 \%$ \\
\hline
\end{tabular}

Although the relevance of such stresses has beer disputed $^{16}$, it is the author's subjective impression tha? many Army wives in Germany suffer one or more of the above stresses, combined with separation froni extended family, postings during the pregnancy, and the् absence of husbands on exercise.

The aetiological factors involved in preterm deliver in this study are similar to those described elsewhere $e^{2,1}$ 要 The proportion of iatrogenically premature babies. $(5.2 \%)$ was greater in the early years when only $66.2 \%$ of mothers had a scan compared with over $90 \%$ in theu 
later years. Given the known risks of induction, including preterm delivery ${ }^{18}$, it is difficult to defend its use "logistically". Of the 22 babies so delivered, one died from respiratory distress and all the others required intensive neonatal care. The pressure on army obstetricians to "Iogistically" induce comes from patients and staff alike, in particular when new postings are arranged around the expected time of delivery or if husbands are likely to be on exercise. A further study (Oak, M - unpublished) has also shown that the liberal use of induction would have little influence on the number of women who deliver in local German hospitals.

The conservative management of SRM had little effect and only increased the mean gestational age from 32.6 weeks on admission to 32.9 weeks at delivery. Although there is a risk of infection from this policy, and $21.6 \%$ of the cases had positive swabs, none of the babies died from sepsis. Doubt has also been cast on the wisdom of stopping labour with tocolytics after 32 weeks $^{19,20}$ other than to allow corticosteroids to be given.

The proportion of VLBW babies in this study was $16.7 \%$ and their mortality was $50 \%$. They constituted $0.69 \%$ of all births at BMH Rinteln compared with the national figure of $1.05 \%$ (OPCS, 1986). The otherwise excellent survival of LBW babies, which is similar to that of the Hammersmith study ${ }^{19}$, is a tribute to the neonatal care which they receive. Neonatal rather than perinatal survival was used as it is more realistic for the preterm infant who may well be kept alive by heroic means for longer than the first week of life. It is not clear whether Caesarean section for the VLBW breech baby improves survival, although retrospective studies have shown a decreased risk of asphyxia and intraventricular haemorrhage $^{21}$. Against this must be weighed the morbidity from a classical section (3 cases). How decisions were made with respect to delivery was not clear from the notes, and in many cases labour was far advanced by the time of admission.

The proportion of LGA babies in this study (36.2\%) is in keeping with other reports ${ }^{22}$. Seventy five percent of all the babies who died in utero from unknown causes or had congenital anomalies incompatible with life, were LGA. Of these 18 infants, 6 were suspected clinically of being small, but either no further action was taken or ultrasound scans were normal. In 3 cases of neural tube defect, AFP estimations and scans had not been done.

Sixteen infants in the study had lethal abnormalities, and where scans were done all but one showed abnormalities of liquor volume or a small baby. Hence, the finding antenatally of a small baby, either clinically or by ultrasound, should be taken seriously and attempts made to exclude abnormality, for example by high resolution scan or amniocentesis if chromosomal abnormality is suspected. Access to Units with excellent scanning facilities, such as King's College Hospital, is not difficult from Germany. It should also be stressed that $7.8 \%$ of the VLBW babies presenting by the breech had congenital abnormalities, and although this modest compared with other studies ${ }^{23}$, emphasizes th need for careful diagnostic tests. Seven of the 16 infan 8 with lethal abnormalities were delivered by Caesarea® section for fetal distress, IUGR or breech presentation and better use of antenatal diagnostic tests might have prevented at least 3 of these (in infants with Potter syndrome and pulmonary hypoplasia).

It has been shown that babies who are LGA have better survival than those of appropriate weight ${ }^{13}$, bif: disability and morbidity is greater. This study did no confirm that, but LGA babies spent significantly les time in SCBU, reflecting their greater maturity. The significantly higher still-birth rate again emphasizes thg need for better antenatal diagnosis and action in the face of an abnormal scan. Two patients complained $\overrightarrow{06}$ decreased fetal movements, and scans were abnormal 4 other cases, where the infant did not have a letha abnormality. Fear of intervention is based on the risk of prematurity, but these 6 infants had gestational ages between 32-37 weeks, and continued intra-uterine starvation may be more harmful than prematurity.

The cost of preterm delivery is not simply finang the human suffering associated with a neonatal de hlo $^{2}$ particularly after prolonged resuscitation or neonatai support, is enormous. Infants who survive, especialle if very small, may have lifelong neurodevelopment abnormalities ${ }^{11,12,13,23}$. Separation at birth rô. predispose to poor relationships between parents anj child, neglect and abuse ${ }^{14}$. It therefore behoves usk identify antenatally factors which may predisposeôt preterm labour, or to act more aggressively when faeed with it. The second strategy is not feasible, as labour i. be silent and rapid; in this study, the average lengt to the first stage in VLBW babies was 3.7 hourso Furthermore, prolongation of pregnancy after SRA does not appear to be successful.

Many studies have identified risk factors associate with preterm deliveries ${ }^{3,4,5,6,7,8,9}$. In this study 209 women $(52.3 \%)$ had at least one suspicious factor suct as age under 20 years, small stature, raised AFP leved multiple pregnancy, anaemia or a previous history of small infant. The high incidence of smoking among thes: women which did not change over the 9 years of the study, should be a matter of concern, particularly as prospective study in 1982 in Rinteln pointed out tha obstetric dangers of smoking ${ }^{24}$. There is evidence that women in Germany smoke more heavily than in the UK(Harvey, P - unpublished.)

A program in California has significantly decreaseg the incidence of preterm labour in a high risk populatio by intensive antenatal care and patient education to bo alert for uterine contractions, backache or vagina discharge ${ }^{25}$; the other vital aspect of the program was. staff training of doctors and nurses. Emphasis was placed on prompt response to patients' complaints of any subtle symptoms, liberal hospitalization and

\section{.}


aggressive treatment of contractions. Patient education is difficult and requires constant reinforcement from both hospital and the medical centres. In theory this is possible, as in the 9 years of the study only 10 women had poor antenatal care. Nevertheless it is this author's impression, on discussion with many women who deliver prematurely or in local German hospitals, that they are given inadequate and inappropriate advice when they contact the medical centre.. This is not surprising, when few general practitioners have post-graduate obstetric experience, and many medical centres have nursing staff who are not trained in midwifery.

The present study has shown that in a population where there is full employment and comprehensive medical care, there is still a relatively high incidence of preterm labour resulting in low birth weight infants. Their excellent survival pays credit to their neonatal care. It is suggested that improvement may only come from patient education and the identification of risk factors, at the booking clinic or during the pregnancy, which predispose to prematurity - smoking, poor nutrition, stress, uterine irritability and a past history of prematurity. A prospective study identifying stresses such as domestic difficulties, and particularly postings during the pregnancy, could be undertaken with discretion. Patient education, however, requires that personnel in medical centres be alert to the subtle symptoms and signs of preterm labour. General practitioners who see pregnant women should have done six months' postgraduate training, and midwives, not general nurses should be available to answer the queries of their patients. Current practice prevents midwives, in those centres fortunate enough to have them, from conducting antenatal clinics and should be reviewed as a matter or urgency. The success of community antenatal care in the UK relies on community midwives who know their patients and their domestic situation, and there is an even stronger case for such a model of care in Germany, given the large distances between medical centres and BMH Rinteln, and the isolation of many young mothers during the course of their pregnancy.

\section{REFERENCES}

1. FuCHS F. Prevention of prematurity. Am J Obstet Gynecol 1976; 126: 809-20.

2. RusH R W, et al. Contribution of preterm delivery to perinatal mortality. Br Med J 1976; 2: 965-8.

3. LIEBERMAN E, et al. Risk factors accounting for racial differences in the rate of premature birth. $N$ Engl J Med 1987; 317: 743-8.
4. STEIN A, et al. Social adversity, low birth weight, and preterm delivery. $\mathrm{Br}$ Med J 1987; 295: 291-3.

5. FEDRICK J and ANDERson A B M. Factors associated with spontaneous preterm birth. BrJ Obstet Gynaecol 1976; 83:? $342-50$.

6. Kleinman J C and Madans J H. The effects of maternal smoking, physical stature, and educational attainment on음 the incidence of low birth weight. Am J Epidemiol 1985; 121: $843-55$.

7. NAEYE, R L. Coitus and associated amniotic-fluide $\overrightarrow{\vec{F}^{\circ}}$ infections. New Engl J Med 1979; 301: 1198-1200.

8. CARR-HILl R A and Hall M H. The repetition of spontaneous preterm birth. BrJ Obstet Gynaecol 1985; 92: $921-28$

9. NeWTON R W and Hunt L P. Psychosocial stress in pregnancy and its relation to low birth weight. $B r M e d ~ J$

1984; 288: $1191-4$.
10. CREASY R K, Gummer B A and Liggins G C. System for $\vec{\circ}$. predicting spontaneous preterm birth. Obstet Gynecol $\vec{c}$ 1980; 55: 692-5.

11. Nickel R E, BENNETT F C and LAMSON F N. School performance of children with birth weights of $1000 \mathrm{~g}$ or less. Э Am J Dis Child 1982; 136: 105-110.

12. Marlow N, D'Souza S W and Chiswick M L. $\vec{\omega}$ Neurodevelopmental outcome in babies weighing less than 2001g at birth. Br Med J 1987; 294: 1582-6.

13. YU V Y H, et al. Outcome of extremely-low-birthweintó infants. Br J Obstet Gynaecol 1986; 93: 162-70.

14. KLEIN M and STERN L. Low birth weight and the batteredo child syndrome. Am J Dis Child 1971; 122: 15-18.

15. PEARCE J M. Management of preterm labour. In, STUDng T (Ed) The Management of Labour. Blackwell Scientifis Oxford, 1985. Ch. 4: 40-67.

16. OMER $\mathrm{H}$, et al. Life stresses and premature labour: rea connection or artefactual findings? Psychosom Med 1986; 48: $362-9$.

17. Meis P J, ERnest J M and Moore M L. Causes of low bienth. weight births in public and private patients. $A m J O b$ s Gynecol 1987; 156: 1165-8.

18. Lewins M J, Whitfield J M and Chance $G$ W. Neonatal respiratory distress: potential for prevention. Can Medo Assoc J 1979;120: 1076-80.

19. LAMONT R F, et al. Spontaneous preterm labour and $\mathbb{D}$ delivery at under 34 weeks' gestation. Br Med J 1983; 286: $\overrightarrow{0}$ 454-7.

20. KING J F, et al. Beta-mimetics in preterm labour: an overview of the randomized controlled trials. BrJ Obstefo Gynaecol 1988; 95: 211-22.

21. STEEL S A and PeARCe M. Delivery of the very low birthweight baby. BrJ Hosp Med 1986; 38: 328-334.

22. SECHER N J, et al. Growth retardation in preterm infants BrJ Obstet Gynaecol 1987; 94: 115-120.

23. Nisell $\mathrm{H}$, Bistolett $P$ and Palme $C$. Preterm breech delivery. Early and late complications. Acta ObsteP Gynaecol Scand 1981; 60: 363-6.

24. Young K R. Effect on birth weight of smoking in pregnancy. J R Army Med Corps 1983; 129: 101-3.

25. Herron M A, KATZ M and Creasy R K. Evaluation of a preterm birth prevention program: preliminary report.o Obstet Gynecol 1982; 59: 452-6.

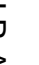

